\title{
The Development of Napoleon's Theorem on the Quadrilateral in Case of Outside Direction
}

\author{
Mashadi $^{1}$, Chitra Valentika ${ }^{2}$, Sri Gemawati ${ }^{1}$, Hasriati $^{1}$ \\ ${ }^{1}$ Analysis and Geometry Group, Department of Mathematics, Faculty of Mathematics and Natural Sciences, University of Riau, Pekanbaru, \\ Indonesia \\ ${ }^{2}$ Department of Mathematics, Faculty of Mathematics and Natural Sciences, University of Riau, Pekanbaru, Indonesia
}

\section{Email address:}

mash-mat@unri.ac.id (Mashadi),chitra.valentika@yahoo.com (C.Valentika),gemawati.sri@gmail.com (S. Gemawati), hasriati.hasri@gmail.com (Hasriati)

\section{To cite this article:}

Mashadi, Chitra Valentika, Sri Gemawati, Hasriati. The Development of Napoleon's Theorem on the Quadrilateral in Case of Outside Direction. Pure and Applied Mathematics Journal. Vol. 6, No. 4, 2017, pp. 108-113. doi: 10.11648/j.pamj.20170604.11

Received: May 6, 2017; Accepted: June 14, 2017; Published: July 18, 2017

\begin{abstract}
In this article we discuss Napoleon's theorem on the rectangles having two pairs of parallel sides for the case of outside direction. The proof of Napoleon's theorem is carried out using a congruence approach. In the last section we discuss the development of Napoleon's theorem on a quadrilateral by drawing a square from the midpoint of a line connecting each of the angle points of each square, where each of the squares is constructed on any quadrilateral and forming a square by using the row line concept.
\end{abstract}

Keywords: Napoleon's Theorem, Napoleon's Theorem on Rectangles, Outside Direction, Congruence

\section{Introductions}

Napoleon's theorem was found by Napoleon Bonaparte (1769-1821), an Emperor of French who had a big interest in geometry [8]. Napoleon's theorem on triangle is equilateral triangle constructed on each side of triangle that leads into outside. Furthermore on each equilateral triangle one can obtain a midpoint that is angle from a new equilateral triangle [2]. The new equilateral triangle can be called as Napoleon's triangle [6].

Napoleon's theorem on the triangle can be proved by using congruence [7] and trigonometry algebra [1, 3 and 5]. Many authors have provided a wide range of alternative proofs as well as developed the Napoleon's theorem, for example [6] develops on the inner Napoleon's theorem, whereas [14] describes it if an isosceles (right angle) of mother triangle is given, what properties must the external and internal Napoleon triangles have? What properties must the external and internal Napoleon's triangles of a mother have to ensure that the mother is an isosceles triangle (right angle) triangle? While [2] developed for the case of the pedal triangle. Many other developments associated with the various theorems in geometry are discussed by a number of authors [3, 4, 5, 10,11, 12 and 13]. The authors in $[5,6,7,8,9$ and 15] developed for the rectangles for the case of inside direction where the proofs are done using a very simple concept.

In this paper we give the development of Napoleon's theorem to the quadrilateral having two pairs of parallel sides and one form of development of Napoleon's theorem for the case of paralellogram. Its development is to construct a quadrilateral formed by the lines connecting the midpoint of each square obtained from the construction. The main content is the process of proofs using a simple geometry concept (the same as in [1,9] and 17). In the final part we give three corollaries in many cases.

\section{Napoleon's Theorem on Quadrilateral}

Before discussing Napoleon's theorem on a quadrilateral, we first give an illustration of the Napoleon theorem for triangles fot the case of outside direction, the illustration can be seen in Figure 1. Similar conditions will also be applied to the quadrilateral 


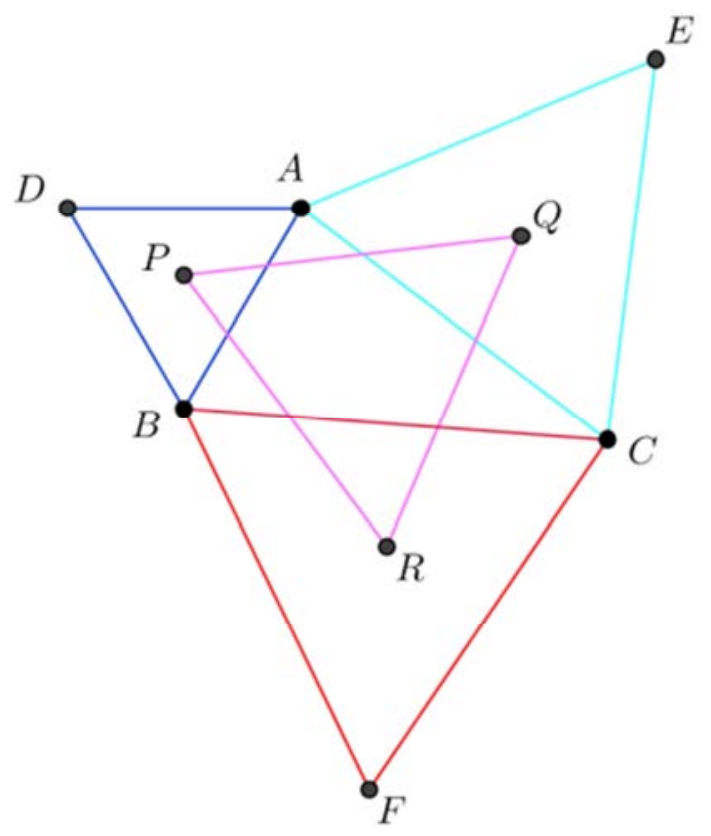

Figure 1. Napoleon's Theorem on triangle for the case of outside direction.

In [11] the development of the Napoleon theorem is carried out for the case of inside direction. While in this paper we do it for the case that leads out, so the development of Napoleon's theorem in this paper for quadrilateral is also done for the case that leads out. If the Napoleon's triangle theorem applied to any construct the triangle with equilateral triangles outward on each side. However, for any quadrilateral we cannot enforce Napoleon's theorem to construct rectilinear direction out on any quadrilateral proficiency level (as an extreme example only create trapezium), it would not produce such a theorem Napoleon, as intended. But if taken rectangle, it is definitely Napoleon's theorem applies. For the following will be made for cases of a parallelogram.

Napoleons' theorem on rectangle will be discussed is on the quadrilateral that has two pairs paralell line, one of them is parallelogram in case of square that constructed outside direction. On $\mathrm{AB}$ side constructed $A B H G$ square, $A D$ side constructed $A D E F$ square, $C D$ side constructed $C D K L$ square, and $B C$ side constructed $B C I J$ square. Then every squares constructed in outside direction. Furthermore every midpoints are connected to shape the square that can be called as Napoleon's quadrilateral in outside direction.

Theorem 1. Provide rectangle in shaping $A B C D$ parallelogram. On each side is constructed $A B H G$ square, $A D E F$ square, $C D K L$ square, and $B C I J$ square in outside direction. For example $M, N, O$, and $P$ are midpoints of square that constructed in outside direction. If the four midpoints are connected they will be shaped $M N O P$ square.

Proof: Alternatif 1. To showing $M N O P$ is square, it will proved by $M N=N O$, and $\angle P M N=90^{\circ}$. from $\triangle G A D$ and $\triangle B A F$, are obtained $A G=A B, \angle G A D=\angle F A B, A D=A F$, so $\triangle G A D \approx \triangle B A F$ [4]. Look at $\triangle G Q T$ and $\triangle B A T$ on figure 4, $\angle T G Q=\angle T B A$ and $\angle G T Q=\angle B T A$, so $\angle G Q T=\angle B A T=90^{\circ}$.

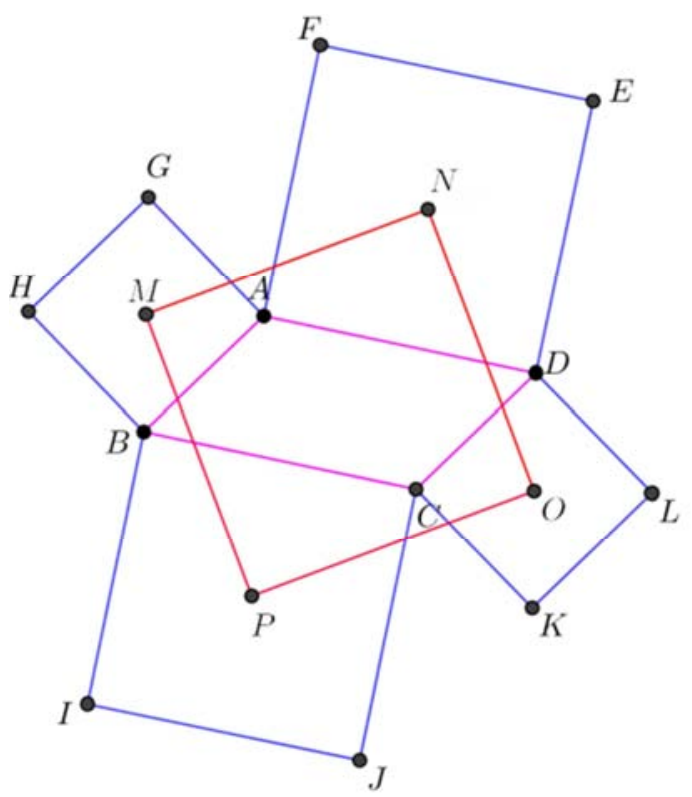

Figure 2. Napoleon's theorem on square.

Furthermore pull line $N P$ and $M O$ then cut it in one point, say point $R$. For example point $S$ cuts point $N P$ and $G D$, and $U$ cuts point $F B$ and $M O$ line. It will be shown that $B F$ is parallel with $P N$. $F N$ and $B P$ is a half diagonal square $A D F E$ and $B C I J$, because of $A D F E$ square and $B C I J$ are parallel then $F N$ is parallel with $B P$. Then pull $F P$ line then it is obtained opposite angle those are $\angle B F P=\angle F P N$ and $\angle B P F$ $=\angle P F N$ that caused $B F$ also parallel with $P N$. Because of $B F$ is parallel with $P N$ so $\angle G Q T=\angle Q S R=\angle M R N=90^{\circ}$. To make it clearer look at Figure 3.

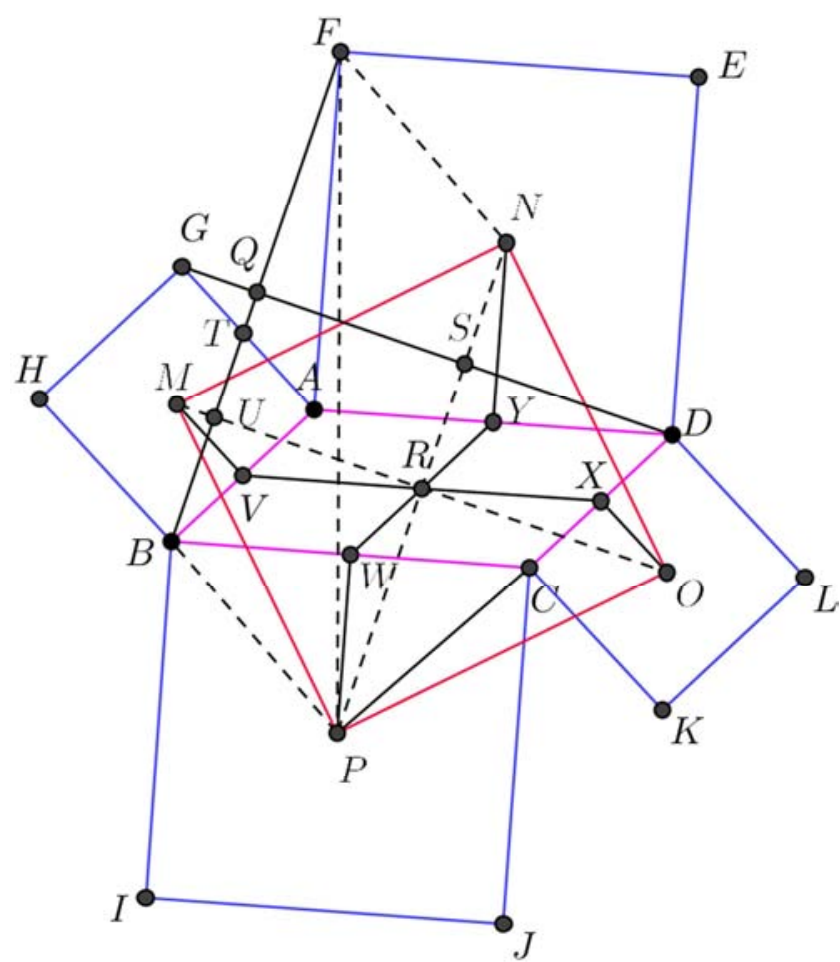

Figure 3. Proof of Napoleon's Theorem on a quadrilateral using congruence. 
For example, $T, U$, and $V$ is the midpoint of the line $A D, C D$, $B C$ and $A B$. From $\triangle M V R$ and $\triangle N S R, M V=S R, \angle M V R=\angle$ $N S R, V R=N S$, then $\triangle M V R \approx \Delta R S N$, causing $M R=R N$. Because $M R=R N$ and $\angle M R N=90^{\circ}$, so $\triangle M R N$ is an isosceles triangle, as well as $\triangle R N O$ that causes $\angle M N R=\angle R N O=45^{\circ}$. Then it is obtained that $\angle M N O=90^{\circ}$, in the same way $\angle O P M=\angle N O P$ $=\angle P M N=90^{\circ}$. From $\triangle \mathrm{MRP}$ and $\triangle N R O$ on, $M R=R O, \angle$ $\mathrm{MRN}=\angle N R O, N R=N R$, then $\triangle M R P \approx \Delta N R O$. So that led to $M N=O N$, then in the same way then $M P=O P . M N O P$ it is clear that the quadrilateral is a square.

Alternative 2. $M N O P$ is a square will be proven by showing $M N=N O$, and $\angle P M N=\angle M N O=90^{\circ}$ with trigonometric approach is by using the cosine rule and sine rule [6].

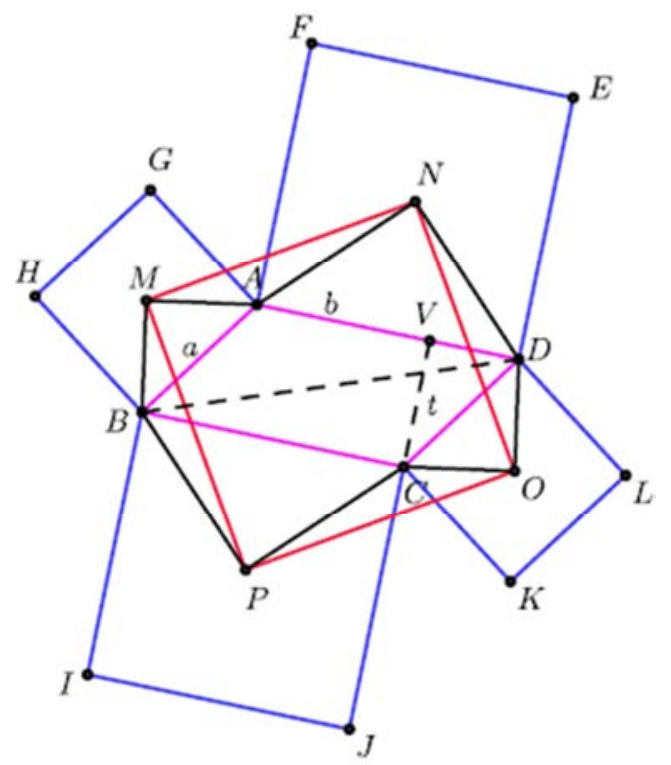

Figure 4. Proof of Napoleon's Theorem on a quadrilateral using trigonometry.

In parallelogram $A B C D$, Let $A B=C D=a$, side $A C=B D$ $=b$, use basic trigonometry to obtain

$$
\begin{aligned}
& \mathrm{AM}=\mathrm{MB}=\mathrm{OC}=\mathrm{OD}=\frac{1}{2} \mathrm{a} \sqrt{2} \\
& \mathrm{AM}=\mathrm{MB}=\mathrm{OC}=\mathrm{OD}=\frac{1}{2} \mathrm{~b} \sqrt{2}
\end{aligned}
$$

So that at $\triangle M A N$ using the cosine rule [5] apply

$$
\begin{gathered}
\mathrm{MN}^{2}=\frac{1}{2} a^{2}+\frac{1}{2} b^{2}-2 \cdot \frac{1}{2} \mathrm{a} \sqrt{2} \cdot \frac{1}{2} \mathrm{~b} \sqrt{2} \cdot \cos \angle \mathrm{MAN} \\
\mathrm{MN}^{2}=\frac{1}{2} a^{2}+\frac{1}{2} b^{2}-a \cdot b \cdot \cos \left(270^{\circ}-\angle \mathrm{BAD}\right) \\
\mathrm{MN}^{2}=\frac{1}{2} a^{2}+\frac{1}{2} b^{2}-a \cdot b \cdot\left(\cos 270^{\circ} \cdot \cos \angle B A D+\right. \\
\left.\quad \sin 270^{o} \cdot \sin \angle B A D\right) \\
\mathrm{MN}^{2}=\frac{1}{2} a^{2}+\frac{1}{2} b^{2}+a \cdot b \cdot \sin \angle \mathrm{BAD}
\end{gathered}
$$

and on $\triangle A B D$ apply

$$
\sin \angle \mathrm{BAD}=\frac{2 . L \Delta \mathrm{ABD}}{a . b}
$$

Substitute the equation (2) to (1) in order to obtain

$$
\begin{aligned}
& \mathrm{MN}^{2}=\frac{1}{2} a^{2}+\frac{1}{2} b^{2}+a \cdot b \cdot \frac{2 \cdot L \Delta \mathrm{ABD}}{a \cdot b} \\
& \mathrm{M} \mathrm{N}=\sqrt{\frac{1}{2} a^{2}+\frac{1}{2} b^{2}+2 \cdot L \Delta \mathrm{ABD}} \\
& \mathrm{M} \mathrm{N}=\sqrt{\frac{1}{2} a^{2}+\frac{1}{2} b^{2}+L \cdot A B C D}
\end{aligned}
$$

Subsequently the $\triangle$ NDO we obtained

$$
\begin{gathered}
\mathrm{NO}^{2}=\frac{1}{2} a^{2}+\frac{1}{2} b^{2}-2 \cdot \frac{1}{2} \mathrm{a} \sqrt{2} \cdot \frac{1}{2} \mathrm{~b} \sqrt{2} \cdot \cos \angle \mathrm{NDO} \\
\mathrm{NO}^{2}=\frac{1}{2} a^{2}+\frac{1}{2} b^{2}-a \cdot b \cdot \cos \left(90^{\circ}+\angle \mathrm{ADC}\right) \\
\mathrm{NO}^{2}=\frac{1}{2} a^{2}+\frac{1}{2} b^{2}-a \cdot b \cdot\left(\cos 90^{\circ} \cdot \cos \angle A D C-\right. \\
\left.\sin 90^{\circ} \cdot \sin \angle A D C\right) \\
\mathrm{NO}^{2}=\frac{1}{2} a^{2}+\frac{1}{2} b^{2}+a \cdot b \cdot \sin \angle \mathrm{ADC}
\end{gathered}
$$

If

$$
t=\frac{L \cdot A B C D}{b} \text { and } \sin \angle \mathrm{ADC}=\frac{t}{a}
$$

Then we have

$$
\sin \angle \mathrm{ADC}=\frac{L \cdot A B C D}{a \cdot b}
$$

Substitute the equation (5) to (4) we obtained

$$
\begin{aligned}
& \mathrm{NO}^{2}=\frac{1}{2} a^{2}+\frac{1}{2} b^{2}+a \cdot b \cdot \frac{L \cdot A B C D}{a \cdot b} \\
& \mathrm{NO}=\sqrt{\frac{1}{2} a^{2}+\frac{1}{2} b^{2}+L \cdot A B C D}
\end{aligned}
$$

Based on the equation (5) and equation (6) it is clear that $M N=N O$. Furthermore, to show $\angle M N O=90^{\circ}$ consider Figure 5 .

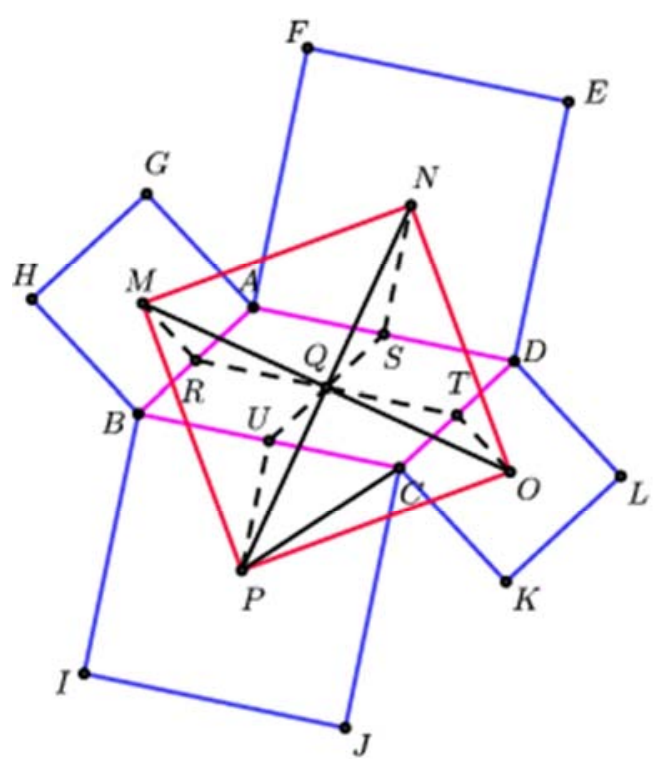

Figure 5. Proof of Napoleon's Theorem on a quadrilateral using trigonometry. 
Then to show $\angle M N O=90^{\circ}$, must first be proven $O Q=$ $N Q$ with the cosine rule. Furthermore, by using the cosine rule on $\triangle N O Q$ obtained $\angle N Q O=90^{\circ}$, so $\triangle N O Q$ is an isosceles triangle that causes $\angle O N Q=\angle N O Q=45^{\circ}$, as well as on $\triangle M N Q$ the same way in order to obtain $\angle M N Q$ $=\angle N M Q=45^{\circ}$. Thus obtained $\angle M N O=90^{\circ}$, in the same way also obtained $\angle \mathrm{NOP}=\angle O P M=\angle N M P=90^{\circ}$. Because $M N=N O$ and $\angle \mathrm{NOP}=\angle O P M=\angle M N Q=\angle N M P=90^{\circ}$, so it is evident that $M N O P$ quadrilateral is a square.

\section{The Development of Napoleon's Theorem on Quadrilateral}

Basically Napoleon's theorem on the quadrilateral can only be developed in a quadrilateral that has two pairs of parallel sides. The following will be given the development of Napoleon's theorem on a parallelogram, theorem developed based on a rectangle to a square case built leading to the outside which is a square formation by connecting endpoints to construct a square formed on the sides of the initial parallelogram.

Theorem 2 Given a parallelogram quadrilateral $A B C D$, and on each side of the square was built leading out. Then draw a line $F G, E L, K J$, and $H I$. Suppose point $Q, R, S$, and $T$ is the midpoint of the fourth line. If the four points are connected, the square formed $Q R S T$.

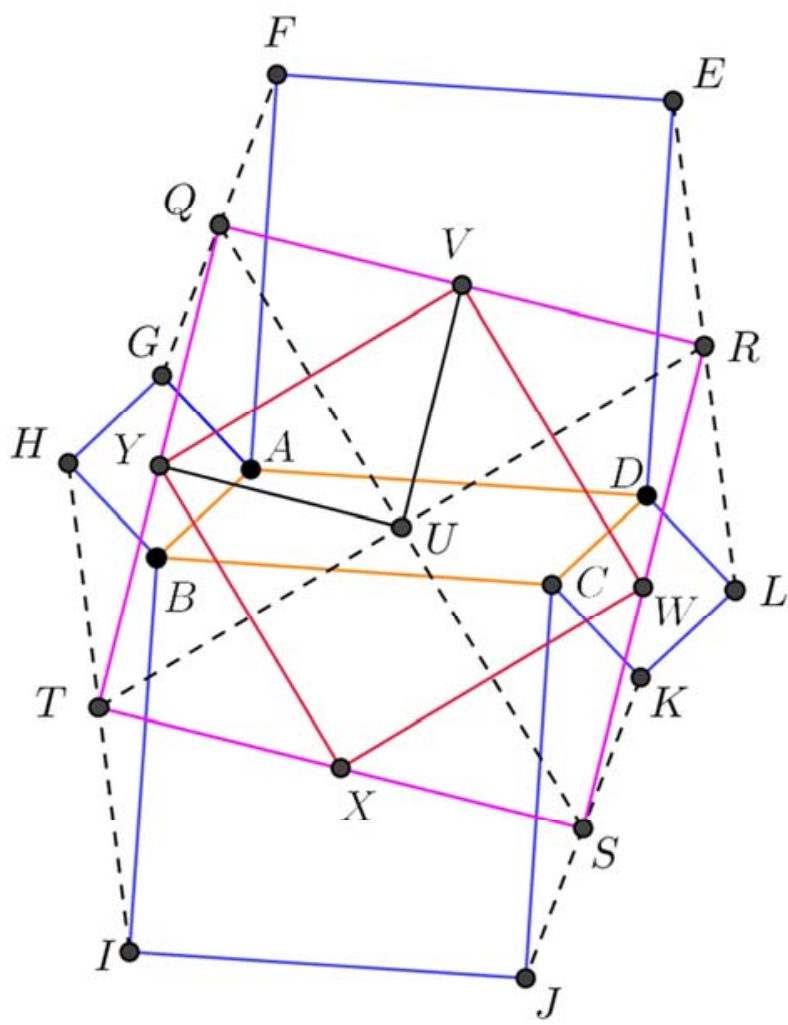

Figure 6. Development of Napoleon's theorem on the quadrilateral.
Proof. Suppose point $Q, R, S$, and $T$ is the midpoint of the line $F G, E L, K J$, and $H I$. To show $Q R S T$ is square it will be proved $T Q=Q R$, and $\angle T Q R=90^{\circ}$. Consider Figure 6, draw a line from point $Q$ to point $S$ and point $R$ to the point $Q$. So the lines $Q S$ and $R Q$ lines intersect at one point, said point $U$. Before the show $T Q=Q R$ will at first show $U T=U R$. Note Figure 4, $U Y=U T, Y T=V R$ so $U T=U R$. Then Note figure 6, $U Y=U T, Y T=V R$ so $U T=U R$. Then look at $\Delta Q U T$ and $\triangle Q U R, U T=U R, \angle T U Q=\angle T U Q$ and $U Q=U Q$ then obtained $T Q=Q R$. From theorem 1, $V U=U Y$, and $\angle V U Y=$ $90^{\circ}$, therefore $\angle Q T R=90^{\circ}$, so it proved $Q R S T$ quadrilateral is a square.

Based on the Theorem 1 and Theorem 2, and by way of connecting the vertex and the lines are connected are three types of effect, that the evidence is not given here because it always can easily be shown, however, given the geometry illustration

Corollary 1. On the square due $M N O P$ and TQRS formed parallel lines $P Q / / S N$ and $M R / / T O$, then the square formed $V W Z U$, and if formed parallel lines $M S / / Q O$ and $T N / / P R$, then the square formed $A_{1} B_{1} C_{1} D_{1}$. The illustration is in Figure 7.

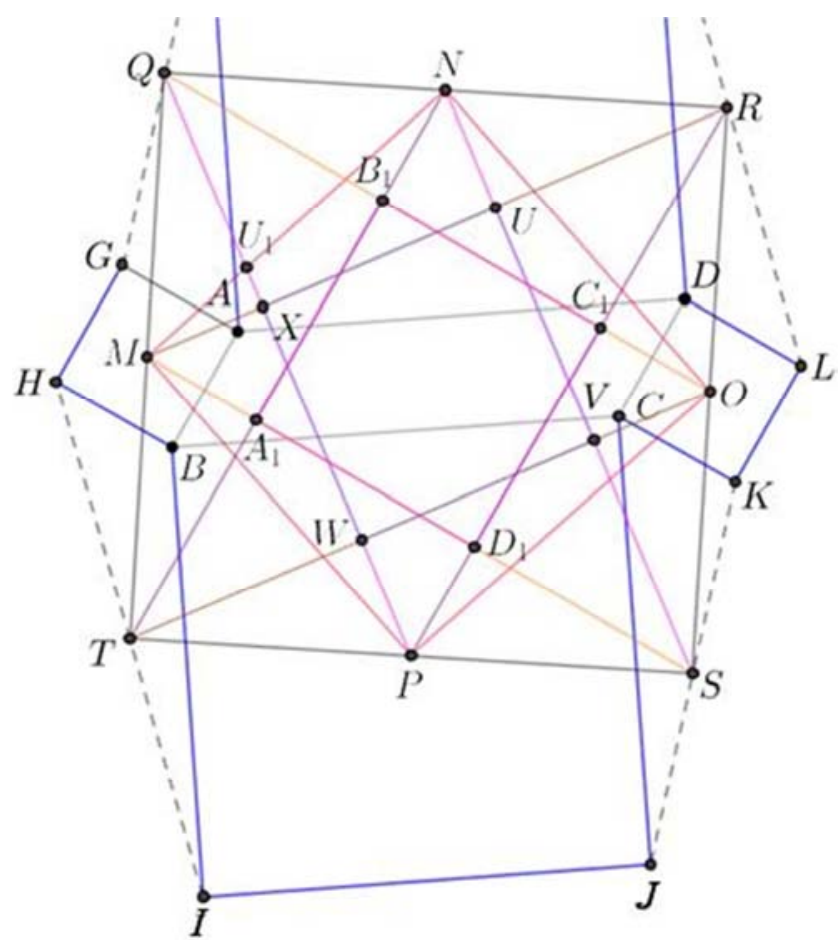

Figure 7. Corollary 1 of Theorem Napoleon in the quadrilateral.

Corollary 2. On the square $V W Z U$ and $A_{1} B_{1} C_{1} D_{1}$ parallel lines $U A_{1} / / V C 1$ and $Z D_{l} / / W B_{1}$ are formed, then a square $K_{l} N_{l} M_{l} H_{l}$ is formed, and if parallel lines $V B_{l} / / U D_{l}$ and $Z D_{l} / / W B_{1}$ are formed, then a square $O_{1} P_{1} Q_{1} R_{l}$ is formed. The ilustration is in Figure 8. 


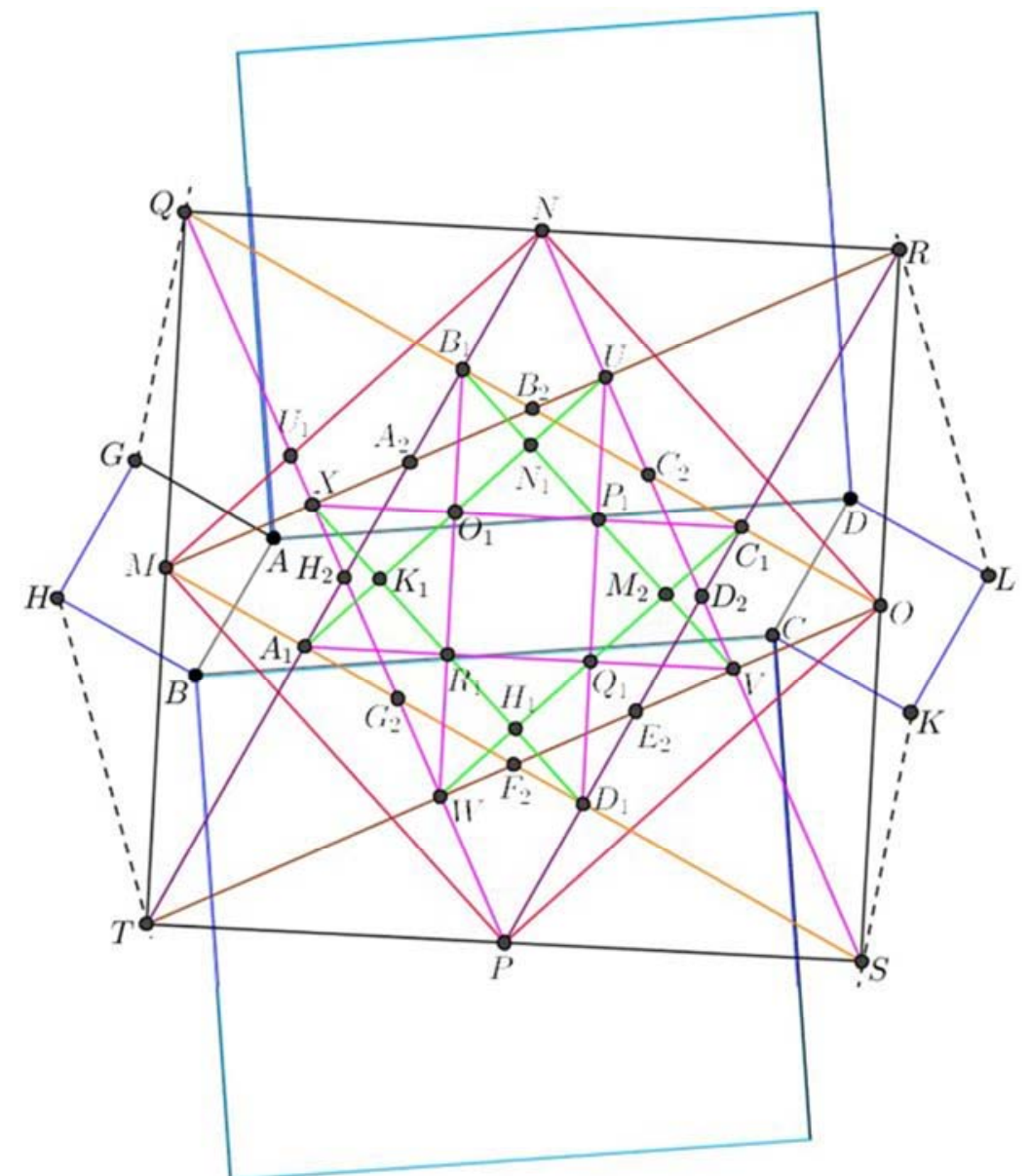

Figure 8. Corollary 2 of Theorem Napoleon in the quadrilateral.

Corollary 3. On the Picture $K_{1} N_{1} M_{1} H_{l}$ and $O_{1} P_{1} Q_{1} R_{1}$ form parallel lines $K_{1} P_{1} / / M_{l} R_{l}$ and $K_{l} Q_{l} / / M_{l} O_{l}$, then they form a square $E_{1} F_{1} I_{1} G_{1}$, and if parallel lines $N_{1} R_{1} / / M_{1} O_{1}$ and $K_{1} Q_{1} / / M_{1} O_{1}$ are formed, then a square $J_{1} L_{1} T_{1} S_{1}$ is formed. Ilustration is in Figure 9.

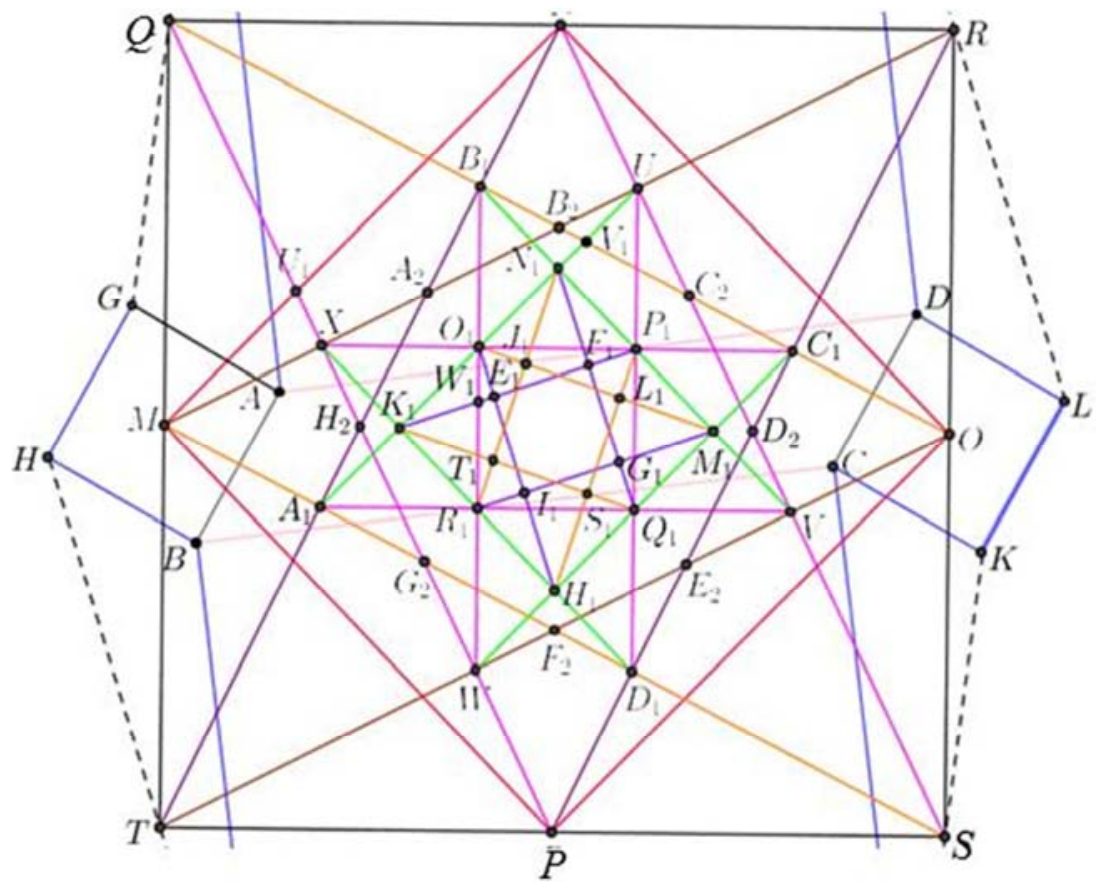

Figure 9. Corollary 3 of Theorem Napoleon in the quadrilateral. 


\section{Conclusion}

After several experiments on Napoleon's Theorem in the quadrilateral we thus observe that Napoleon's theorem applied only to the quadrilateral which possess two pairs of parallel sides like a square, rhombus, rectangle, and parallelogram. Napoleon's Theorem in the ranks of the cases led to the outside that is if the square was built on each side of the square center of the fourth point would be to the square Napoleon called quadrilateral outside. Proof of that is done by using the concept of congruence. Development of Napoleon on a quadrilateral theorem can be developed to form a square on the midpoint of the line so as to form a new square, and forming a square with the concept of parallel lines that intersect.

\section{References}

[1] Ainul Wardiyah, Mashadi and Sri Gemawati, Relationship of Lemoine circle with a symmedian point, JP Journal Math. Sci., 17 (2) (2016), 23-33.

[2] B. J. McCartin, Mysteries of the Equilateral Triangle, Hikari Ruse, 2010.

[3] B. Grunbaum, Is Napoleon's theorem really Napoleon's theorem, The American Mathematical Monthly, 119 (2012), 495-501.

[4] G. A. Venema, Exploring advanced euclidean geometry with Geometer's Sketchpad, http://www.math.buffalostate.edu/giambrtm/MAT521/eeg.pdf, accessed 26 july 2016 .

[5] J. A. H. Abed, A proof of Napoleon's theorem, The General Science Journal, (2009), 1-4.

[6] J. E. Wetzel, Converses of Napoleon's theorem, The American Mathematical Monthly, 99 (1992), 339-351.
[7] Mashadi, Buku Ajar Geometri, Pusbangdik Universitas Riau, Pekanbaru, 2012.

[8] Mashadi, Geometri Lanjut, Pusbangdik Universitas Riau, Pekanbaru, 2015.

[9] Mashadi, S. Gemawati, Hasriati and H. Herlinawati, Semi excircle of quadrilateral, JP Journal Math. Sci. 15 (1 \& 2) (2015), 1-13.

[10] Mashadi, S. Gemawati, Hasriati and P. Januarti, Some result on excircle of quadrilateral, JP Journal Math. Sci. 14 (1 \& 2) (2015), 41-56.

[11] Mashadi, Chitra Valentika and Sri Gemawati, International Journal of Theoritical and Applied Mathematics, 3 (2), (2017), $54-57$.

[12] M. Corral, Trigonometry, http://www.biomech.uottawa.ca/fran09/enseignement/notes/ trgbook.pdf, accessed 26 july 2016.

[13] N. A. A. Jariah, Pembuktian teorema Napoleon dengan pendekatan trigonometri, http://www.academia.edu/12025134/ Isi NOVIKA ANDRI ANI_AJ_06121008018, accessed 6 Oktober 2015.

[14] P. Bredehoft, Special Cases of Napoleon Triangles, Master of Science, University of Central Missouri, 2014.

[15] P. Lafleur, Napoleon's Theorem, Expository paper, http://www.Scimath.unl.edu/MIM/files/MATEexamFiles, accessed 24 November 2015.

[16] V. Georgiev and O. Mushkarov, Around Napoleon's theorem, http://www.dynamat.v3d.sk/ uploaddf 20120221528150.pdf, accessed 24 july 2016.

[17] Zukrianto, Mashadi and S Gemawati, A Nonconvex Quadrilateran and Semi-Gergonne Points on it: Some Results and Analysis, Fundamental Journal of Mathematics and Mathematical Sciences, 6 (2), (2016), 111-124. 